\title{
Systemic Lysis Protects against the Effects of Platelet Activation during Coronary Thrombolysis
}

Desmond J. Fitzgerald, Marie Hanson, and Garret A. FitzGerald

Divisions of Clinical Pharmacology and Cardiology, Vanderbilt University, Nashville, Tennessee 37232

\begin{abstract}
Systemic lysis may protect against the platelet activation and ongoing thrombosis associated with coronary thrombolysis. To address this hypothesis, we compared urokinase and tissuetype plasminogen activator (t-PA) given intravenously in a chronic, canine model of coronary thrombosis. T-PA $10 \mu \mathrm{g} / \mathrm{kg}$ per min induced reperfusion in $55 \pm 7$ min but complete reocclusion occurred in 9/10 animals. Reocclusion was prevented by combining t-PA with 7E3, an antibody to the platelet glycoprotein IIb/IIIa which abolished ex vivo platelet aggregation. $A$ similar time to reperfusion was seen with urokinase 750-1,000 $\mathrm{U} / \mathrm{kg}$ per min. In contrast to t-PA, complete reocclusion occurred in only $1 / 20$ cases $(P<0.001$ vs. t-PA), despite evidence of continued platelet activation in vivo and platelet aggregation ex vivo. Furthermore, this did not reflect a difference in the clearance of the two plasminogen activators. However, plasma fibrinogen was undetectable after urokinase in contrast with t-PA. Furthermore, in animals treated with prourokinase 20 $\mu \mathrm{g} / \mathrm{kg}$ per min, reocclusion (4/7) correlated with the degree of systemic lysis. To determine whether platelet activation modified the response to urokinase, it was combined with 7E3. 7E3 $0.8 \mathrm{mg} / \mathrm{kg}$ reduced the time to reperfusion with t-PA $(30 \pm 5, n$ $=6 ; P=0.025)$, but not with urokinase $(56 \pm 8$ vs. $62 \pm 6, P$ $=n s)$. Systemic lysis protects against the propensity of continued thrombosis during coronary thrombolysis to delay reperfusion and induce reocclusion. This may modify the requirement for adjunctive antiplatelet therapy. (J. Clin. Invest. 1991. 88:1589-1595.) Key words: thrombolysis • platelets • coronary thrombosis
\end{abstract}

\section{Introduction}

Coronary thrombolysis with either streptokinase (1) or tissuetype plasminogen activator (t-PA) ${ }^{1}(2)$ is accompanied by evidence of platelet activation. Clinical and experimental studies suggest that this increased platelet activity is of functional importance. Thus, inhibition of platelets by a variety of pharmacologically distinct agents accelerates reperfusion and prevents acute reocclusion in response to t-PA (3-5) and improves survival in patients (6). Activated platelets provide a number of

Address correspondence to Desmond Fitzgerald, M.D., Center for Cardiovascular Science, Dept. of Medicine and Experimental Therapeutics, University College Dublin, Mater Hospital, Dublin, Ireland. Recei.

1. Abbreviations used in this paper: GP, glycoprotein; proUK, prourokinase; UK, urokinase; t-PA, tissue-type plasminogen activator.

\section{J. Clin. Invest.}

(C) The American Society for Clinical Investigation, Inc.

$0021-9738 / 91 / 11 / 1589 / 07 \quad \$ 2.00$

Volume 88, November 1991, 1589-1595 cofactors required for the maximal expression of prothrombinase activity (7). Platelet aggregation may also enhance procoagulant activity by localizing coagulation enzymes or protecting them from inhibitors (8). Thus, platelet activation during coronary thrombolysis may trigger thrombin activation and ongoing thrombosis. Consistent with this hypothesis, specific inhibition of thrombin exerts effects similar to those seen with antiplatelet agents, without altering the biochemical evidence for platelet activation (9). Furthermore, partial inhibition of platelets during coronary thrombolysis increases the sensitivity to antithrombin therapy (9). These data suggest that thrombin activation is one of the major consequences of the increase in platelet activation that accompanies thrombolytic therapy and that this, in turn, may induce ongoing thrombosis.

It would be predicted, therefore, that reocclusion would occur less frequently with agents that induced a degree of systemic plasminemia sufficient to deplete circulating clotting factors. Furthermore, these agents would be less dependent on very potent antiplatelet therapy for maximum expression of their clinical effect. To explore further the role of thrombosis in this setting, we compared the effects of urokinase (UK) with more clot selective agents, t-PA and prourokinase (proUK), in an experimental model of coronary thrombolysis. In addition, we used 7E3, an $\mathrm{F}\left(\mathrm{ab}^{\prime}\right)_{2}$ fragment of an antibody to the platelet glycoprotein (GP)IIb/IIIa (10), to determine the role of platelets in modulating the response to urokinase.

\section{Methods}

\section{Materials}

ADP and bovine thrombin were purchased from the Sigma Chemical Co., St. Louis, MO. Urokinase (a gift from Dr. Jack Henkin, Abbott Laboratories, Abbott Park, IL) was obtained from a human kidney cell line and was primarily of the low molecular weight form with an activity of $\sim 10,000 \mathrm{IU} / \mathrm{mg}$ (11). Tissue-type plasminogen activator (a gift from Dr. Stuart Bunting, Genentech Inc., South San Francisco, CA) was obtained from Escherichia coli transfected with a plasmid carrying the human gene for t-PA and was of clinical grade with an activity of $\sim 580,000 \mathrm{IU} / \mathrm{mg}$. Prourokinase (a gift from Dr. Carlo Patrono, Farmitalia Carla Erba, Milan, Italy) was obtained from $E$. coli transfected with a plasmid carrying the human gene for prourokinase. It was a nonglycosylated protein with $<0.4 \%$ intrinsic activity and with amidolytic and fibrin plate activities of 135,000 and $154,000 \mathrm{IU} / \mathrm{mg}$, respectively. 7E3 (a gift from Dr. Harvey Berger, Centocor, Malvern, PA) is an $\mathrm{F}\left(\mathrm{ab}^{\prime}\right)_{2}$ fragment of a murine antibody that cross-reacts with primate and canine GPIIb/IIIa $(10,12)$.

\section{Experimental model}

All animal experiments were reviewed and approved by the Animal Care Committee at Vanderbilt University. The model used was a closed chest, canine model of coronary thrombosis, as previously described $(13,14)$. Briefly, male mongrel dogs $(17-23 \mathrm{~kg})$ were anesthetized with pentobarbital $30 \mathrm{mg} / \mathrm{kg}$ and ventilated with a respirator (Harvard Apparatus, South Natick, MA). Through a thoracotomy, a needle electrode was implanted in the circumflex coronary artery distal to a Doppler flow probe (Crystal Biotech, Holliston, MA). The termi- 
nals of the electrode and flow probe were brought to the surface in a subcutaneous pouch and the animal allowed to recover.

\section{Experimental procedure}

5-7 d after surgery, when TXA $\mathrm{T}_{2}$ biosynthesis had returned to normal, the animal was sedated (acepromazine $1 \mathrm{mg} / \mathrm{kg}$ plus morphine 1-2 $\mathrm{mg} / \mathrm{kg}$ ) and the terminals of the flow probe and electrode recovered. The flow probe was connected to a Doppler flowmeter (545C-4; Bioengineering, Univ. of Iowa, Iowa City, IA) in series with a polygraph (model 79D; Grass Instrument Co., Quincy, MA) for continuous recording of coronary blood flow velocity. A 200- $\mu$ A current was passed through the electrode to induce endothelial injury and coronary thrombosis. Thrombotic occlusion of the coronary artery, detected as abolition of the Doppler flow signal, occurred in 1-2 $\mathrm{h}$ and the current was discontinued $30 \mathrm{~min}$ later. $2 \mathrm{~h}$ after complete coronary occlusion, the thrombolytic agent was administered as a continuous infusion through a peripheral vein and was continued until $10 \mathrm{~min}$ after reperfusion (detected as an abrupt return of the flow signal). Following reperfusion, coronary blood flow velocity was monitored for a further $2 \mathrm{~h}$. Complete reocclusion was defined as zero flow with no spontaneous reperfusions.

\section{Study groups}

Six groups of animals were studied. They included: $(a) \mathrm{t}-\mathrm{PA} 10 \mu \mathrm{g} / \mathrm{kg}$ per min i.v. alone $(n=10) ;(b) \mathrm{t}-\mathrm{PA} 10 \mu \mathrm{g} / \mathrm{kg}$ per min plus 7E3 0.8 $\mathrm{mg} / \mathrm{kg}(n=6) ;(c)$ urokinase $1,000 \mathrm{IU} / \mathrm{kg}$ per $\min (n=8) ;(d)$ urokinase as a bolus of $5,600 \mathrm{IU} / \mathrm{kg}$ followed by an infusion of $750 \mathrm{IU} / \mathrm{kg}$ per min $(n=12) ;(e)$ urokinase plus 7E3 $0.8 \mathrm{mg} / \mathrm{kg}(n=8) ;(f)$ prourokinase 20 $\mu \mathrm{g} / \mathrm{kg}$ per $\min (n=7)$. The plasminogen activator was administered as an intravenous infusion beginning $2 \mathrm{~h}$ after complete coronary occlusion and continued until $10 \mathrm{~min}$ after reperfusion. 7E3 was administered at a dose of $0.8 \mathrm{mg} / \mathrm{kg}$ i.v. $30 \mathrm{~min}$ before initiating the urokinase or t-PA infusion. At this dose, $85 \%$ of platelet GPIIb/IIIa receptors are occupied and platelet aggregation ex vivo is abolished $(10,12)$. Furthermore, this dose has no hemodynamic effect and does not alter the platelet count in this model (5).

\section{Fibrinogen and platelet studies}

Blood was withdrawn from a peripheral vein into $3.8 \%$ sodium citrate (9:1, vol:vol) at timed intervals. For platelet studies, platelet rich plasma was prepared by centrifuging the blood at $900 \mathrm{~g}$ for $50 \mathrm{~s}$. Platelet poor plasma was prepared from the residual blood by centrifuging at $900 \mathrm{~g}$ for $10 \mathrm{~min}$. For fibrinogen studies, blood was centrifuged at $900 \mathrm{~g}$ for $10 \mathrm{~min}$ and the sample analyzed without freezing on the day of study. Platelet aggregation was performed in platelet rich plasma at $37^{\circ} \mathrm{C}$ by light transmission (Biodata Pap 4; Biodata Corp., Hatboro, PA) as previously described (5). Agonists (arachidonic acid 0.16-0.66 $\mathrm{mM}$, ADP 2.5-30 $\mu \mathrm{M}$, U46619 0.25-2 $\mu \mathrm{M}$, thrombin 1-5 mU) were added in volumes of $10 \%$ or less to $500-\mu 1$ aliquots of platelet rich plasma.

Fibrinogen concentration was determined as thrombin clottable protein using a fibrometer (Becton Dickinson Immunocytometry Systems, Mountain View, CA). The coefficient of variation between measurements on the same sample was $4.9 \%$. Each sample was run in triplicate. The coefficients of variation for repeated sampling $(n=3)$ at 30 -min intervals in two dogs were $1 \%$ and $0.8 \%$, respectively. Bleeding rates were determined from a wound on the chest wall used to retrieve the flow probe and electrode terminals. The wound was standardized so that it was $1 / 2$ inch in length and involved the full thickness of the skin and subcutaneous tissues. Bleeding rate was determined by packing the wound with gauze and determining the increase in weight of the gauze hourly throughout the experiment.

\section{Fibrin autography}

Fibrin autography was performed as previously described (15). Blood from a peripheral vein was withdrawn into a syringe containing acidified $3.8 \%$ citrate $(\mathrm{pH} 3.9)$ and the plasma was separated and stored at $-70^{\circ} \mathrm{C}$ immediately. Acidified plasma was added to sampling buffer and applied to a $7.5 \%$ polyacrylamide gel with a stacking gel of $4 \%$. After SDS-polyacrylamide gel electrophoresis (16), the gel was washed with $0.25 \%$ Triton X-100, overlaid on a fibrin plate containing $2 \mu \mathrm{M}$ plasminogen, and incubated for $16 \mathrm{~h}$. Free and complexed plasminogen activators were detected as clear zones following protein staining or under dark-ground illumination.

\section{Biochemical analysis}

Urine was obtained at intervals during the experiment through a catheter for determination of 2,3-dinor-TXB $\mathbf{T}_{2}$, a major enzymatic metabolite of $\mathrm{TXA}_{2}$ (17). The metabolite was determined by isotope dilution technique using a deuterated internal standard and quantitation by gas chromatography, mass spectrometry, as previously described (18).

\section{Statistics}

Reperfusion rates were compared by Fischer's exact test. The times to reperfusion, metabolite excretion, and bleeding rates were compared between groups by a Kruskal Wallis one-way analysis of variance and by a subsequent Mann Whitney test for comparison between groups. The effect of fibrinogen depletion on reocclusion was examined by chi-square using the Yates correction for small sample sizes. All data are expressed as the mean \pm SEM.

\section{Results}

\section{Time to reperfusion and reocclusion}

The time to reperfusion was similar for t-PA, urokinase, and prourokinase (Table I). Although it has been reported that the response to urokinase can be improved by administering $25 \%$ of the dose as a bolus (19), a similar reperfusion rate was seen when urokinase was administered by continuous infusion in this model. Therefore, both doses were considered together in the subsequent analysis. There was a marked difference in the rate of reocclusion between the t-PA and the urokinase groups. In all but one case (9/10), complete reocclusion occurred $35 \pm 9$ min after discontinuing t-PA. In contrast, complete reocclusion occurred in only $1 / 20$ animals $(P<0.001$ vs. t-PA) following withdrawal of urokinase (Table I, Fig. 1). Although complete reocclusion rarely occurred following reperfusion with urokinase, reperfusion flow was frequently interrupted by cyclical variations, where flow velocity gradually declined and then abruptly increased (Fig. 1).

Table I. Time to Reperfusion and Reocclusion Rates after Coronary Thrombolysis with Urokinase and $t-P A$

\begin{tabular}{lrcc}
\hline \multicolumn{1}{c}{ Treatment } & $n$ & $\begin{array}{c}\text { Reperfusion } \\
\text { time }\end{array}$ & $\begin{array}{c}\text { Reocclusion } \\
\text { rate }\end{array}$ \\
\hline & & $\min$ & $\%$ \\
t-PA $10 \mu \mathrm{g} / \mathrm{kg}$ per min & 10 & $55 \pm 7$ & 90 \\
Urokinase $1,000 \mathrm{U} / \mathrm{kg}$ per min & 8 & $57 \pm 7$ & 0 \\
Urokinase 5,600 U/kg & & & \\
$\quad+750 \mathrm{U} / \mathrm{kg} \mathrm{per} \mathrm{min}$ & 12 & $65 \pm 8$ & 8 \\
Prourokinase $20 \mu \mathrm{g} / \mathrm{kg}$ per min & 7 & $75 \pm 10$ & 57 \\
t-PA plus 7E3 0.8 mg/kg & 6 & $30 \pm 5^{*}$ & 0 \\
Urokinase plus 7E3 0.8 mg/kg & 8 & $56 \pm 8$ & 0 \\
& & &
\end{tabular}

Reocclusion occurred in the majority of animals after reperfusion with t-PA. In contrast, complete reocclusion rarely occurred after reperfusion with urokinase. Pretreatment with 7E3 reduced the time to reperfusion with t-PA and prevented reocclusion. In contrast, the time to reperfusion with urokinase was unaltered by $7 \mathrm{E} 3$. ${ }^{*} P=0.025$. 

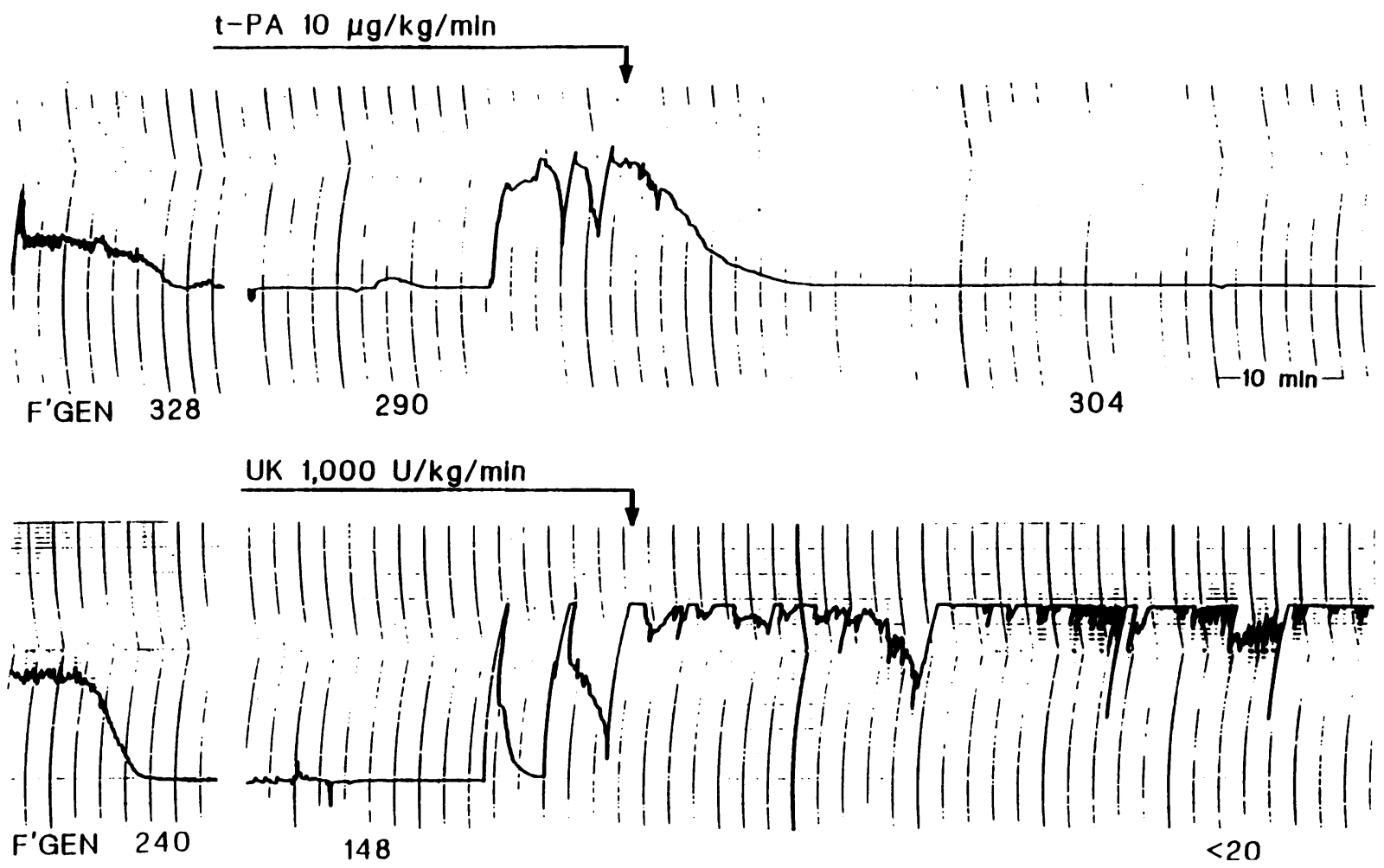

Figure 1. Comparison of t-PA and urokinase in the chronic canine model of coronary thrombosis. Coronary flow velocity tracings from two experiments. In the upper panel, coronary thrombosis was induced resulting in zero flow velocity. $2 \mathrm{~h}$ later, reperfusion was induced with t-PA. However, shortly after discontinuing t-PA, complete reocclusion occurred and persisted for over $2 \mathrm{~h}$ of observation. In contrast, when reperfusion was induced with urokinase (lower panel), complete reocclusion does not occur over the 2-h observation period. Note the presence of cyclical flow variations following reperfusion with urokinase (see also Fig. 5).

\section{Fibrin autography and plasma fibrinogen}

The difference in reocclusion rates between t-PA and urokinase was not due to a difference in the plasma clearance of drugs. Thus, little lytic activity was detected by fibrin autography in plasma 30 min after discontinuation of either t-PA or urokinase (Fig. 2). However, as expected, there were marked differences in the degree of systemic lysis between the two drugs, as determined by measurement of plasma fibrinogen. Plasma fibrinogen was determined during the infusion and again at $2 \mathrm{~h}$ after reperfusion, long after the plasminogen activator had cleared from plasma. The 2-h sample, therefore, is a measure of the peak effect and avoids artifacts due to ex vivo lysis. In animals treated with t-PA, plasma fibrinogen decreased from $292 \pm 37 \mathrm{mg} / \mathrm{dl}$ at baseline to $221 \pm 29 \mathrm{mg} / \mathrm{dl}$ during the infusion and $227 \pm 34 \mathrm{mg} / \mathrm{dl} 2 \mathrm{~h}$ after reperfusion $(n=7$, $P=\mathrm{ns})$. In contrast, in animals treated with urokinase, plasma fibrinogen fell by $>50 \%$ during the infusion (241 \pm 28 to $106 \pm 26 \mathrm{mg} / \mathrm{dl}, n=17 ; P<0.001)$ and was undetectable $2 \mathrm{~h}$ after reperfusion.

The relevance of the degree of systemic lysis to the reocclusion rate was demonstrated in experiments with prourokinase (Table II). Prourokinase induced reperfusion in $75 \pm 10 \mathrm{~min}(n$ $=7$ ), similar to that seen with urokinase and t-PA. Reocclusion occurred in 4/7 cases and appeared related to the degree of systemic lysis. In those that failed to reocclude, plasma fibrinogen was undetectable. In contrast, in animals that reoccluded, there was, in all but one case, a smaller reduction in plasma fibrinogen. No relationship was demonstrated between reocclusion and either $\mathrm{TXA}_{2}$ biosynthesis or the bleeding rate for prourokinase (Table II). When all three groups were considered together, the relationship between patency and the lack of detectable fibrinogen in plasma was significant $(P<0.005$ by chi-square). This was also true when only the proUK and t-PA groups were considered $(P<0.05)$.

\section{Platelet function and bleeding in response to urokinase}

Platelet aggregation was determined before and at $30 \mathrm{~min}$ of urokinase administration. Urokinase induced a small reduction in platelet aggregation in response to ADP $(68 \pm 5 \%$ vs. $73 \pm 9 \%, n=5 ; P=\mathrm{ns}$ ) but did not alter the response to $\mathrm{U} 46619$ (77 $\pm 4 \%$ vs. $70 \pm 5 \%$ during infusion) or arachidonic acid ( $70 \pm 10 \%$ vs. $68 \pm 13 \%$ ). Similarly, the threshold concentration of thrombin for aggregation was unaltered. In another group of six animals treated with urokinase $1,000 \mathrm{U} / \mathrm{kg}$ per min, we examined platelet aggregation at $1 \mathrm{~h}$ of urokinase or upon reperfusion and at 1-2 $\mathrm{h}$ after reperfusion. Again, platelet aggregation to U46619, thrombin, and arachidonic acid were unaltered (Fig. 3; Table III). ADP-induced aggregation decreased modestly following the administration of urokinase ( $36 \pm 11 \mathrm{vs.}$ $78 \pm 5 \%$ at baseline, $n=6 ; P=0.024)$. This did not reflect a direct effect of urokinase, as platelet aggregation remained impaired after discontinuation of the drug $(33 \pm 11 \%, n=5 ; P$ $=0.043$ ). Inhibition of the response to ADP, however, was largely overcome by increasing the concentration of the agonist.

As an index of in vivo platelet activation, urinary excretion of 2,3-dinor- $\mathrm{TXB}_{2}$ was determined throughout the experiment. A small increase in excretion of this metabolite occurred 


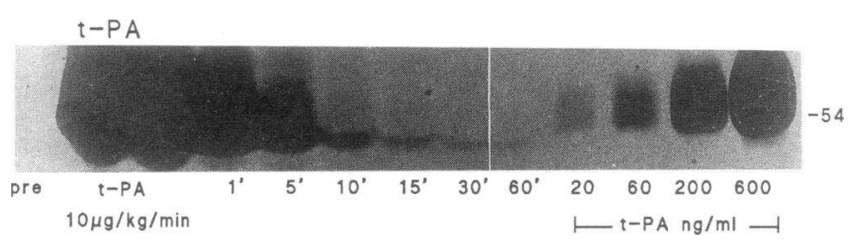

UROKINASE

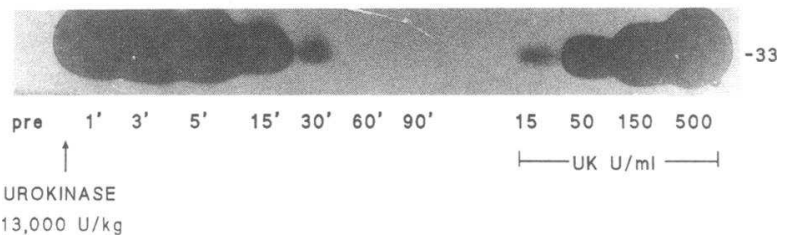

Figure 2. Fibrin autography of plasma obtained during and after t-PA (upper panel) and urokinase (lower panel) administration in the dog. Each is a single experiment and is representative of three experiments. Shown here are the lytic zones corresponding to the unbound, active plasminogen activator. This was confirmed by running authentic standards added to buffer, as shown. The size of the lytic zones correlates with the concentration of the plasminogen activator. For both t-PA and urokinase, clearance was rapid with little drug detected 30 min after withdrawal of the infusion.

during the induction of coronary thrombosis (Table IV). After reperfusion, urinary excretion of 2,3-dinor- $\mathrm{TXB}_{2}$ increased markedly with all three plasminogen activators and this increase was maintained throughout the period of observation (Table IV). The extent of the increase after reperfusion varied widely between animals and was most marked for prourokinase.

Bleeding from the skin incision was minimal before administration of thrombolytic therapy (Fig. 4). After thrombolysis with urokinase, the rate of bleeding increased $(2.5 \pm 0.7$ vs. $0.2 \pm 0.1 \mathrm{ml} / \mathrm{h} ; P=0.012$ ) and it was noted that this tended to occur immediately before reperfusion. The increase in bleeding persisted over the period of observation after reperfusion. Simi-

Table II. The Effect of Prourokinase in the Experimental Model oj Coronary Thrombosis

\begin{tabular}{rrrrrrr}
\hline \multirow{2}{*}{ REOCCL } & \multicolumn{2}{c}{ Fibrinogen } & \multicolumn{2}{c}{ Bleeding rate } & \multicolumn{2}{c}{ TXM } \\
\hline min & \multicolumn{2}{c}{ mg/dl } & \multicolumn{2}{c}{ ml/min } & \multicolumn{2}{c}{$n g / m g c r$} \\
& pre & post & pre & post & pre & post \\
& & & & & & \\
32 & 295 & 135 & 0.3 & 2.2 & 2.2 & 124 \\
54 & 235 & nd & 0.3 & 7.4 & 2.3 & 42 \\
66 & 132 & 110 & 0.2 & 6.0 & - & -1.5 \\
94 & 195 & 115 & 0.3 & 7.6 & 2.6 & 87 \\
$>120$ & 195 & nd & 0.2 & 17.5 & 2.1 & 81 \\
$>120$ & 220 & nd & 0.2 & 2.5 & 1.5 & 31 \\
$>120$ & 320 & nd & 0.2 & 4.4 & 3.5 & 73 \\
& & & & & & \\
\hline
\end{tabular}

Prourokinase was administered in a dose of $20 \mu \mathrm{g} / \mathrm{kg}$ per min commencing $2 \mathrm{~h}$ after occlusion. Complete, irreversible reocclusion (REOCCL) occurred in 4/7 animals. (TXM, urinary 2,3-dinor-TXB ; $_{2}$ cr, creatinine; nd, none detected).

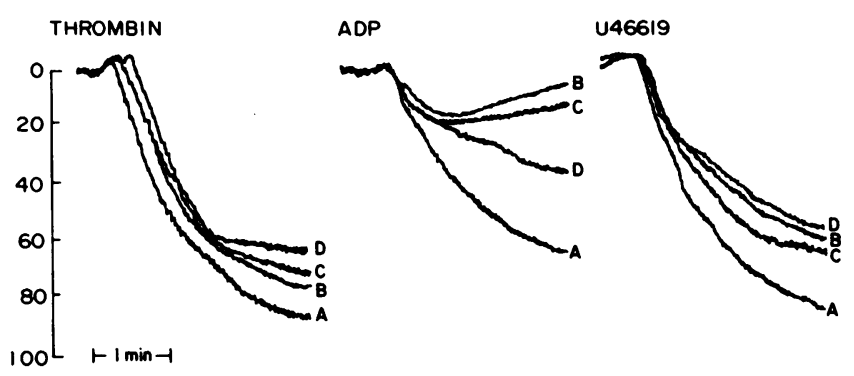

Figure 3. Platelet aggregation in response to thrombin, ADP, and U46619 at baseline $(A)$, during the infusion of urokinase $1,000 \mathrm{U} / \mathrm{kg}$ per min $(B)$, at reperfusion (80 min of urokinase) $(C)$, and $2 \mathrm{~h}$ after reperfusion $(D)$. Plasma fibrinogen was $295 \mathrm{mg} / \mathrm{dl}$ in sample A, before urokinase. In all other samples, no fibrinogen was detected.

lar results were obtained with t-PA $(1.7 \pm 0.7$ vs. $0.2 \pm 0.04 \mathrm{ml} / \mathrm{h}$; $P=0.008)$ and there was no significant difference between treatments (Fig. 4). Increased bleeding was also seen with prourokinase and was unrelated to the degree of systemic lysis (Table II).

\section{Effect of 7E3 on the response to urokinase}

7E3, the antibody to the platelet GPIIb/IIIa, was administered to six animals treated with t-PA and eight treated with urokinase. Administration of 7E3 abolished ex vivo platelet aggregation (data not shown) and markedly augmented the increase in bleeding seen with urokinase $(10.2 \pm 2.0$ vs. $2.5 \pm 0.7 \mathrm{ml} / \mathrm{min} ; P$ $<0.05)$ and t-PA $(7.9 \pm 1.9$ vs. $1.7 \pm 0.7 \mathrm{ml} / \mathrm{min}$ with t-PA alone; $P<0.05$ ) (Fig. 4). In t-PA treated animals, 7E3 reduced the time to reperfusion by almost $50 \%(30 \pm 5$ vs. $55 \pm 7 \mathrm{~min}, P$ $=0.025$ ). In contrast, in animals treated with urokinase, 7E3 had no effect on the time to reperfusion $(56 \pm 8 \mathrm{~min}$ vs. $62 \pm 6$ min; $P=\mathrm{ns}, n=8$ ). In animals pretreated with $7 \mathrm{E} 3$, cyclical flow variations, which occurred commonly in animals treated with urokinase alone, were not detected over the $2 \mathrm{~h}$ of observation after reperfusion (Fig. 5).

\section{Discussion}

In experimental models of arterial thrombolysis, platelet activation profoundly limits the response to t-PA, delaying reperfusion and inducing acute reocclusion (3-5). Thus, inhibitors of platelet activation, including thromboxane $A_{2}$ and serotonin receptor antagonists and prostacyclin, enhance the response to t-PA. A similar effect is seen with $7 E 3$, an $F\left(a b^{\prime}\right)_{2}$ fragment of

Table III. Platelet Aggregation in Response to ADP, U46619, Thrombin, and Arachidonic Acid in Six Animals before and after Reperfusion with Urokinase 1,000 U/kg per min

\begin{tabular}{llccc}
\hline & ADP & U46619 & AA & Thrombin \\
\hline Preurokinase & $75 \pm 5 \%$ & $79 \pm 7 \%$ & $82 \pm 3 \%$ & $7.8 \pm 4.0$ \\
Reperfusion & $36 \pm 11 \%^{*}$ & $79 \pm 9 \%$ & $80 \pm 5 \%$ & $7.5 \pm 3.8$ \\
$1-2$ h after reperfusion & $33 \pm 11 \%^{*}$ & $71 \pm 3 \%$ & $80 \pm 6 \%$ & $8.1 \pm 3.0$
\end{tabular}

Note that in samples drawn at $1-2 \mathrm{~h}$ after reperfusion, plasma fibrinogen was undetectable. The results for thrombin are reported as the threshold concentration $(\mathrm{mU} / \mathrm{ml})$, the lowest concentration that gave a full aggregation response. ${ }^{*} P<0.05$ vs. preurokinase. 
Table IV. Urinary Excretion of 2,3-dinor-TXB in $\mathrm{ng} / \mathrm{mg}$ Creatinine before (pre) and after Complete Coronary Occlusion and for $2 h$ after Reperfusion

\begin{tabular}{lccccc}
\hline \multicolumn{1}{c}{ Treatment } & $n$ & Pre & Occlusion & \multicolumn{2}{c}{ Reperfusion } \\
\hline & & & & $1 h$ & $2 h$ \\
t-PA & 6 & $3.7 \pm 0.6$ & $10.4 \pm 0.5^{*}$ & $58 \pm 17^{* \neq}$ & $56 \pm 18^{* \ddagger}$ \\
Urokinase & 8 & $4.0 \pm 0.4$ & $5.1 \pm 0.8^{*}$ & $25 \pm 7^{* \neq}$ & $36 \pm 8^{* \ddagger}$ \\
Prourokinase & 6 & $2.4 \pm 0.3$ & $4.7 \pm 0.9^{*}$ & $67 \pm 10^{* \neq}$ & $92 \pm 24^{* \neq}$
\end{tabular}

${ }^{*} P<0.05$ vs. pre; ${ }^{\ddagger} P<0.05$ vs. occlusion. Excretion of the metabolite for prourokinase was significantly $(P<0.05)$ higher than for urokinase after reperfusion.

an antibody to platelet GPIIb/IIIa. Antagonism of platelet GPIIb/IIIa inhibits platelet aggregation and the other consequences of ligand binding to this receptor, including tyrosine kinase-specific protein phosphorylation, calcium entry into the cell and the release response (20-22). Platelets are a major source of phospholipid and factor Va, cofactors which greatly accelerate the conversion of prothrombin to thrombin $(7,23$, 24). Furthermore, activated platelets express binding sites for factor Va and may localize prothrombinase activity on their surface (25). Thus, a major consequence of enhanced platelet activity during coronary thrombolysis may be increased thrombin formation and ongoing thrombosis. Consistent with this hypothesis, specific thrombin inhibition accelerates reperfusion and prevents reocclusion to an extent similar to that achieved with platelet inhibition $(5,9)$. Therefore, by inducing an anticoagulant state, systemic lysis may reduce the risk of reocclusion and decrease the adverse effects of platelet activation during coronary thrombolysis.

To address this hypothesis, we compared urokinase and t-PA in a closed chest, canine model of coronary thrombosis. These compounds are known to differ markedly in their clot specificity, with urokinase inducing a greater systemic lytic ef-

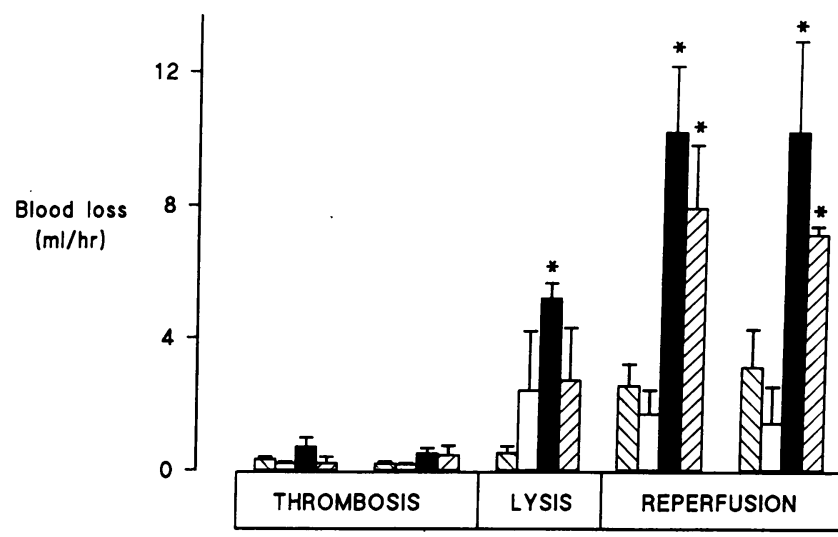

Figure 4. The bleeding rate, determined as blood loss in milliliters per hour, from a standardized incision on the thorax before, during (lysis), and after the administration of urokinase or t-PA alone and combined with 7E3. Bleeding increased during the administration of t-PA and UK and after reperfusion, but was not different for the two drugs. Combining UK or t-PA with 7E3 markedly increased the bleeding rate. urokinase; $\square, \mathrm{t}-\mathrm{PA} ; \mathrm{n}$, urokinase + 7E3; t-PA + 7E3. ${ }^{*} P$ $<0.05$ vs. plasminogen activator alone. fect. As previously shown $(5,9)$, reperfusion with t-PA was complicated by complete reocclusion in almost every case. In contrast, patency was maintained by pretreatment with an $F\left(a b^{\prime}\right)_{2}$ fragment of an antibody, 7E3, to the platelet glycoprotein IIb/IIIa, demonstrating the major role of platelets in mediating reocclusion. In contrast to $t-P A$, reperfusion with urokinase was rarely complicated by complete reocclusion.

The disparity between the drugs was not due to a difference in their clearance; this was similar for the two thrombolytic agents based on measurements of free drug by fibrin autography. There was also no evidence that this reflected inhibition of platelet aggregation by urokinase. Firstly, platelet aggregation in response to activation of the TXA $\mathrm{T}_{2}$ receptor (U46619, arachidonic acid) and to thrombin, the major mediators of platelet activation during coronary thrombolysis $(5,14)$ was unaltered. There was a modest reduction in platelet aggregation to ADP after urokinase administration. The mechanism of this effect is uncertain, but does not appear to be a direct effect of the drug. Furthermore, it is unlikely to be due to a reduction in plasma fibrinogen, since platelets aggregate after extensive washing and resuspension in buffer (26). We and others have reported a similar response to t-PA $(5,27)$. Furthermore, based on experiments with a variety of antiplatelet agents, inhibition of platelet activation would need to be very profound (complete abolition of platelet aggregation to all agonists) to prevent reocclusion (5). Secondly, there was evidence of ongoing platelet activation in vivo, based on an increase in urinary 2,3-dinor-TXB $\mathrm{TX}_{2}$. Excretion of this metabolite reflects systemic biosynthesis of $\mathrm{TXA}_{2}$, the major cyclooxygenase product of arachidonic acid in platelets, and is increased in a variety of conditions associated with platelet activation (2830). Although excretion of this metabolite was less marked in urokinase treated animals, the difference was not significant and in prourokinase treated animals urinary 2,3-dinor- $\mathrm{TXB}_{2}$ was unrelated to plasma fibrinogen (Table II). Finally, there was in vivo evidence that platelet function was similar for the two drugs. Thus, bleeding rates increased to the same extent after t-PA and urokinase administration. When an antiplatelet agent (7E3) was added to urokinase, bleeding increased markedly as with t-PA. These data suggest that platelet function was indeed largely intact in animals treated with urokinase alone.

These studies suggest that the difference in the reocclusion rates between t-PA and urokinase was related to the degree of systemic lysis, in contrast to the lack of relationship with impaired platelet function. This hypothesis is supported by the results obtained with prourokinase. The dose of prourokinase was selected to achieve a time to reperfusion similar to that seen with urokinase and t-PA. At this dose there was a variable degree of systemic lysis, as has been reported in man (31). Reocclusion occurred in about $50 \%$ of animals, but not in those with little detectable fibrinogen. Moreover, the maintenance of patency did not appear to reflect altered platelet activity, as there was no relationship with $\mathrm{TXA}_{2}$ biosynthesis or hemostatic function (Table II). More recently, we have demonstrated that highly selective regimens of low dose t-PA combined with prourokinase $10 \mu \mathrm{g} / \mathrm{kg}$ per min in this model are complicated by reocclusion in every case (Fitzgerald, D. J., et al., unpublished data).

We examined the effect of 7E3 on the response to the thrombolytic agents to compare further the role of platelets in determining the response to t-PA and urokinase. As we and others 

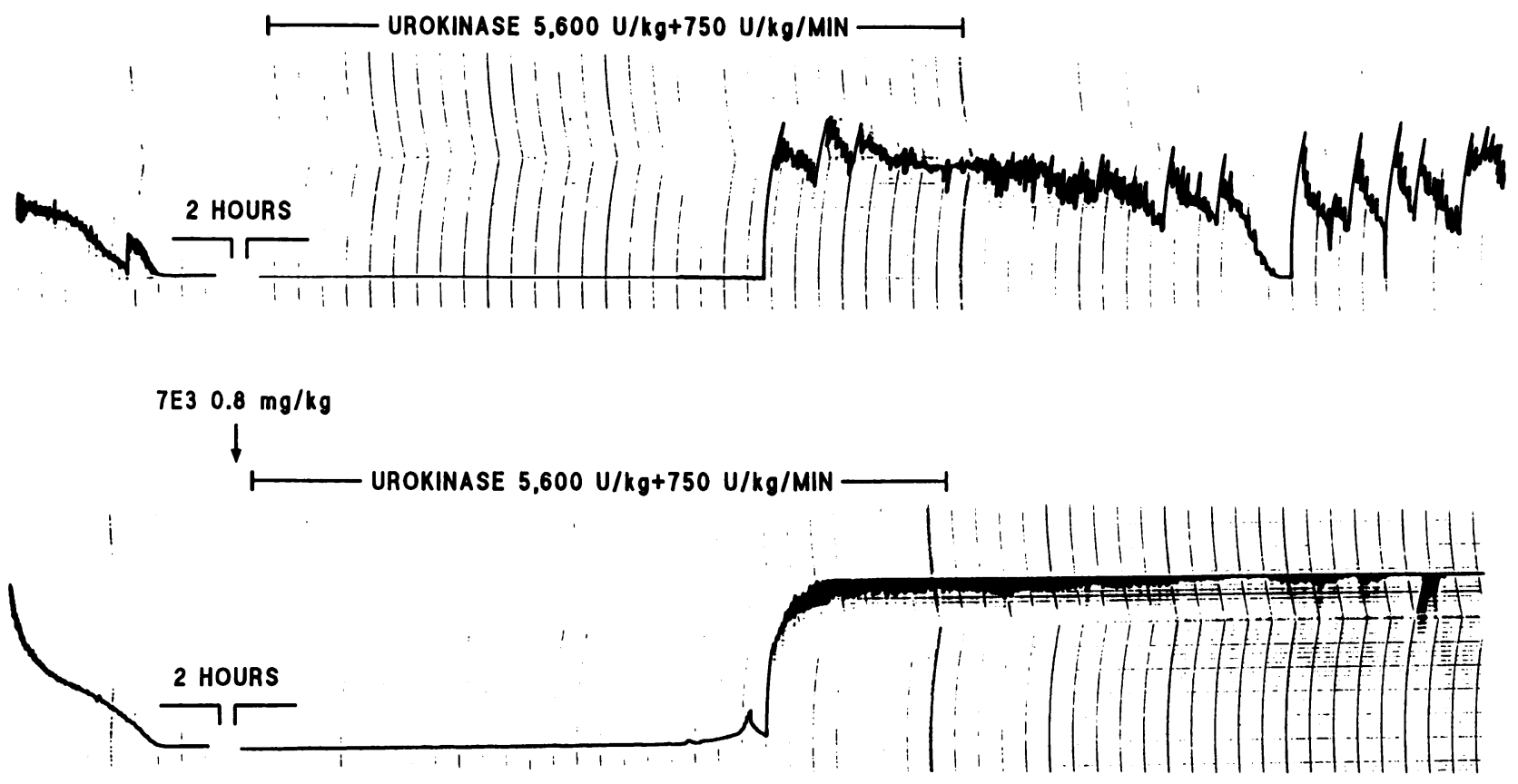

Figure 5. Effect of 7E3 on the response to urokinase in the chronic canine model of coronary thrombosis. Coronary flow velocity tracings from two experiments. In the upper panel, coronary thrombosis was induced resulting in zero flow velocity. $2 \mathrm{~h}$ later, urokinase was administered, resulting in reperfusion in $43 \mathrm{~min}$. Complete reocclusion never occurred over $2 \mathrm{~h}$ of observation. However, reperfusion flow was interrupted repeatedly by cyclical variations. In the lower panel, $7 \mathrm{E} 30.8 \mathrm{mg} / \mathrm{kg}$ was administered $30 \mathrm{~min}$ before urokinase. The time to reperfusion was unaltered but the cyclical flow variations were abolished. (Representative of eight experiments).

have shown previously $(3,5), 7 \mathrm{E} 3$ greatly modified the response to t-PA in this model. In particular, 7E3 reduced the time to reperfusion with t-PA by almost $50 \%$, in addition to preventing reocclusion. In contrast, 7E3 did not alter the time to reperfusion with urokinase. The only demonstrable effect was that spontaneous cyclical variations in reperfusion flow were abolished. Previous evidence suggests that these cyclical flow variations are platelet dependent (9) and are further evidence that platelet function is preserved following urokinase administration.

These data suggest, therefore, that systemic lysis protects against the effects of platelet activation during coronary thrombolysis. This may be due to a reduction in circulating fibrinogen or reflect the anticoagulant response to its degradation products (32). Alternatively, depletion of other coagulation factors may be involved (33). The resulting inhibition of thrombosis during the induction of lysis may underlie the lack of effect of 7E3 on reperfusion time. A similar mechanism may explain the low reocclusion rate with urokinase. In our experiments, the beneficial effects of systemic lysis occurred without a further alteration in hemostatic function over that seen with $\mathrm{t}$-PA. This is similar to findings in man, where the frequency of bleeding complications with t-PA and streptokinase are comparable and appear unrelated to the degree of systemic lysis (6, 34,35 ).

In conclusion, these studies provide evidence that systemic lysis protects against reocclusion and may decrease the requirement for potent antithrombotic therapy. These data imply that a strategy based on increasing the clot specificity of thrombolytic regimens may impose a particular requirement for potent adjunctive therapy to prevent the consequences of attendant platelet activation.

\section{Acknowledgments}

Supported by grants from the National Institutes of Health (HL-30400 and HL-40056), Abbott Pharmaceuticals, Farmitalia Carla Erba, and Daiichi Seiyaku. Dr. D. Fitzgerald is a recipient of a Veterans Administration Merit Award. Dr. G. FitzGerald is the William Stokes Professor of Experimental Therapeutics.

\section{References}

1. Fitzgerald, D. J., F. Catella, L. Roy, and G. A. FitzGerald. 1988. Marked platelet activation in vivo after intravenous streptokinase. Circulation. 77:142150.

2. Kerins, D. M., L. Roy, G. A. FitzGerald, and D. J. Fitzgerald. 1989. Platelet and vascular function during coronary thrombolysis with tissue-type plasminogen activator. Circulation. 80:1718-1725.

3. Yasuda, T., H. K. Gold, J. T. Fallon, R. C. Leinbach, J. L. Guerrero, L. E. Scudder, M. Kanke, D. Shealy, M. J. Ross, D. Collen, and B. S. Coller. 1988. Monoclonal antibody against the platelet glycoprotein (GP) IIb/IIIa receptor prevents coronary artery reocclusion after reperfusion with recombinant tissue-type plasminogen activator in dogs. J. Clin. Invest. 81:1284-1291.

4. Golino, P., J. H. Ashton, P. Glas-Greenwalt, J. McNatt, L. M. Buja, and J. T. Willerson. 1988. Mediation of reocclusion by thromboxane $A_{2}$ and serotonin after thrombolysis with tissue-type plasminogen activator in a canine preparation of coronary thrombosis. Circulation. 77:678-674.

5. Fitzgerald, D. J., F. Wright, and G. A. FitzGerald. 1989. Increased thromboxane biosynthesis during coronary thrombolysis: evidence that platelet activation and thromboxane $A_{2}$ modulate the response to tissue-type plasminogen activator. Circ. Res. 65:83-94.

6. ISIS-2 (Second International Study Group of Infarct Survival) Collaborative Group. 1988. Randomised trial of intravenous streptokinase, oral aspirin both or neither in 17,187 cases of acute myocardial infarction: ISIS-2. Lancet. ii:349-360.

7. Rosing, J., J. L. M. L. van Rijn, E. M. Bevers, G. van Dieijen, P. Comfurius, and R. F. A. Zwaal. 1985. The role of activated platelets in prothrombin and factor X activation. Blood. 65:319-332.

8. Teitch, J. M., and R. D. Rosenberg. 1983. Protection of factor Xa from neutralization by heparin-antithrombin complex. J. Clin. Invest. 71:1383-1387.

9. Fitzgerald, D. J., and G. A. FitzGerald. 1989. Role of thrombin and throm- 
boxane $\mathrm{A}_{2}$ in reocclusion following coronary thrombolysis with tissue-type plasminogen activator. Proc. Natl. Acad. Sci. USA. 86:7585-7589.

10. Coller, B. S. 1985. A new murine monoclonal antibody reports an activation-dependent change in the conformation and/or microenvironment of the platelet-GPIIb/IIla complex. J. Clin. Invest. 76:101-108.

11. Barlow, G. H., and L. Lazer. 1972. Characterization of the plasminogen activator from human embryo kidney cells: comparison with urokinase. Thromb. Res. 1:201-207.

12. Coller, B. S., and L. E. Scudder. 1986. Inhibition of dog platelet function by in vivo infusion of $\mathrm{F}\left(\mathrm{ab}^{\prime}\right)_{2}$ fragments of a monoclonal antibody. Blood. 66:1456-1459.

13. Romson, J. L., D. W. Haack, and B. R. Luchessi. 1980. Electrical induction of coronary artery thrombosis in the ambulatory canine: a model for in vivo evaluation of antithrombotic agents. Thromb. Res. 17:841-853.

14. Fitzgerald, D. J., J. Fragetta, and G. A. FitzGerald. 1988. Prostaglandin endoperoxides modulate the response to thromboxane synthase inhibition during coronary thrombosis. J. Clin. Invest. 82:1708-1713.

15. Granelli-Peperno, A., and E. Reich. 1978. A study of proteases and protease-inhibitor complexes in biological fluids. J. Exp. Med. 178:223-234.

16. Laemmli, U. K. 1970. Cleavage of structural proteins during the assembly of the head of bacteriophage T4. Nature (Lond.). 227:680-685.

17. Roberts, L. J., B. J. Sweetman, and J. A. Oates. 1981. Metabolism of thromboxane $\mathrm{B}_{2}$ in man. J. Biol. Chem. 256:8384-8391.

18. Nowak, J., J. J. Murray, J. A. Oates, and G. A. FitzGerald. 1987. Biochemical evidence of a chronic abnormality in platelet and vascular function in healthy individuals who smoke cigarettes. Circulation. 76:6-14.

19. Klabunde, R. E., C. C. Hemenway, S. J. Mohrman, J. Henkin, and S. F. Badylak. 1988. Optimizing the bolus/infusion ratio for intravenous administration of urokinase in dogs. Thromb. Res. 50:857-864.

20. Ferrell, J. E., and G. S. Martin. 1989. Tyrosine-specific protein phosphorylation is regulated by glycoprotein IIb-IIIa in platelets. Proc. Natl. Acad. Sci. USA. 86:2334-2338.

21. Sinigaglia, F., A. Bisio, M. Torti, C. L. Balduni, G. Bertolino, and C. Balduni. 1988. Effect of GPIIb-IIIa complex ligands on calcium movement and cytoskeleton organization in activated platelets. Biochem. Biophys. Res. Commun. 154:258-264.

22. Mousa, S. A., T. M. Reilly, L. Pease, J. Bozarth, A. Chiu, H. L. Walton, S. Mohamed, R. Knabb, and A. Racanelli. 1990. Inhibition of human platelet plasminogen activator inhibitor-1 release by GPIIb/IIIa receptor antagonists. Fibrinolysis. 4(Suppl. 3):43.
23. Heldebrandt, C. M., R. J. Butkowski, S. P. Bajaj, and K. G. Mann. 1973. Thrombin activation. J. Biol. Chem. 248:7149-7163.

24. Miletich, J. P., C. M. Jackson, and P. W. Majerus. 1977. Interaction of coagulation factor Xa with human platelets. Proc. Natl. Acad. Sci. USA. 74:40334037.

25. Tracy, P. B., and S. Solymoss. 1988. Synergistic effect of platelet agonists on platelet prothrombinase (Ilase) activity and platelet factor $\mathrm{V}$ release. Circulation. 78:II-120.

26. Mustard, J. F., D. W. Perry, N. G. Ardlie, and M. A. Packham. 1974 Preparation of suspensions of washed platelets from humans. Br. J. Haematol. 22:193-198.

27. Mickelson, J. K., P. J. Simpson, M. Cronin, J. W. Homeister, E. Laywell, J. Kitzen, and B. R. Luchessi. 1990. Antiplatelet antibody [7E3 F $\left(\mathrm{ab}^{\prime}\right)_{2}$ ] prevents rethrombosis after recombinant tissue-type plasminogen activator-induced coronary artery thrombolysis in a canine model. Circulation. 81:617-627.

28. Fitzgerald, D. J., L. Roy, F. Catella, and G. A. FitzGerald. 1986. Platelet activation in unstable coronary disease. $N$. Engl. J. Med. 315:983-989.

29. Reilly, I. A. G., J. B. Doran, B. Smith, and G. A. FitzGerald. 1986 Increased thromboxane biosynthesis in a human preparation of platelet activation: biochemical and functional consequences of selective inhibition of thromboxane synthase. Circulation. 73:1300-1309.

30. Fitzgerald, D. J., W. Rocki, R. Murray, G. Mayo, and G. A. FitzGerald. 1990. Thromboxane $A_{2}$ synthesis in pregnancy-induced hypertension. Lancet. 335:751-754.

31. Van de Werf, F., J. Vanhaecke, H. de Geest, M. Verstrate, and D. Collen. 1986. Coronary thrombolysis with recombinant single chain urokinase-type plasminogen activator in patients with acute myocardial infarction. Circulation. 74:1066-1070.

32. Marder, V. J., and N. R. Shulman. 1969. High molecular weight derivatives of human fibrinogen produced by plasmin. II. Mechanisms of their anticoagulant activity. J. Biol. Chem. 244:2120-2124.

33. Sherry, S., and E. Gustafson. 1985. The current and future use of thrombolytic therapy. Annu. Rev. Pharmacol. Toxicol. 25:423-431.

34. Wilcox, R. G., C. G. Olsson, A. M. Skene, G. von der Lippe, G. Jensen, and J. R. Hampton. 1988. Trial of intravenous plasminogen activator for mortality reduction in acute myocardial infarction. Anglo-Scandinavian study of early thrombolysis (ASSET). Lancet. ii:525-530.

35. International Study Group. 1990. In-hospital mortality and clinical course of 20,891 patients with suspected acute myocardial infarction randomised between alteplase and streptokinase with or without heparin. Lancet. ii:71-75. 